\title{
Comparative study of elastic properties and mode I fracture energy of carbon nanotube/epoxy and carbon fibre/epoxy laminated composites
}

\author{
Jyotikalpa Bora and Sushen Kirtania * (1)
}

\begin{abstract}
A comparative study of elastic properties and mode I fracture energy has been presented between conventional carbon fibre (CF)/epoxy and advanced carbon nanotube (CNT)/epoxy laminated composite materials. The volume fraction of CNT fibres has been considered as 15\%,30\%, and 60\% whereas; the volume fraction of CF has been kept constant at 60\%. Three stacking sequences of the laminates viz.[0/0/0/0], [0/90/0/90] and [0/30/-30/90] have been considered in the present analysis. Periodic microstructure model has been used to calculate the elastic properties of the laminated composites. It has been observed analytically that the addition of only 15\% CNT in epoxy will give almost the same value of longitudinal Young's modulus as compared to the addition of 60\% CF in epoxy. Finite element (FE) analysis of double cantilever beam specimens made from laminated composite has also been performed. It has been observed from FE analysis that the addition of 15\% CNT in epoxy will also give almost the same value of mode I fracture energy as compared to the addition of $60 \%$ CF in epoxy. The value of mode I fracture energy for [0/0/0/0] laminated composite is two times higher than the other two types of laminated composites.
\end{abstract}

Keywords: Carbon nanotube, Carbon fibre, Finite element analysis, Elastic properties, Mode I fracture energy

\section{Introduction}

Discovery of carbon nanotubes (CNTs) by Iijima in 1991 brought a revolution in research in the field of nanotechnology [1]. CNTs have excellent mechanical, thermal and electrical properties [2]. The combination of excellent properties has made CNTs an ideal candidate for reinforcement in matrix for structural applications. For light weight polymers, CNT has emerged as an ideal reinforcement due to its excellent mechanical and thermal properties. The CNT-reinforced polymer composites possess high specific strength due to which they have become very compelling structural materials not only in aerospace which requires light weight but also in some other applications such as automotive,

*Correspondence: sushen@tezu.ernet.in

Department of Mechanical Engineering, Tezpur Univeristy, Assam, India electronics, biomedical, sporting goods etc.[3]. The inplane properties of structural composites are excellent. But due to the weak through thickness properties, laminated composites are prone to delamination which is the most common mode of failure for laminated composites. Kormanikova and Kotrasova [4] calculated the longitudinal Young's modulus, transverse Young's modulus, inplane shear modulus and Poison ratio of a unidirectional laminate and reported that in a frame of the analytical homogenization, comparatively better results obtained from the periodic microstructure model. Recently, Kirtania and Chakraborty [5] determined the thermoelastic properties of CNT/epoxy composite by considering a representative volume element. Kageyama et al. [6] fabricated RF-MEMS switch and reported that the $\mathrm{Au}-\mathrm{Au}$ / CNT composite contact switch exhibits higher life cycle, reliability and power capacity than the $\mathrm{Au}-\mathrm{Au}$ contact 
switch. The interlaminar fracture toughness of laminated composites could be increased by using CNTs as reinforcements have been reported by different researchers. Zhou et al. [7] reported an increase of mode I fracture toughness of carbon fibre/epoxy laminate by $125 \%$ using micro-sized carbon fibre interleaf grafted with functional nano-sized carbon nanotube. Li et al. [8] reported an increase in mode I fracture toughness by $174.81 \%$ of glass fibre reinforced polymer composite using CNT bucky paper as interleaf. Quan et al. [9] fabricated MWCNT reinforced $\mathrm{CF}$ fabric/epoxy composite and reported that the addition of $1 \mathrm{wt} \% \mathrm{CNT}$ in composite, the mode I fracture toughness increased by $25 \%$.

It has also been reported that sometimes the addition of CNTs into the composite did not produce desired results. The CNT-reinforced composites fabricated using conventional methods such as dispersion, buckypapers etc. are sometimes unable to show the exceptional properties due to their reinforcing nano building blocks. This can be attributed to low volume fraction and agglomeration tendency of the CNTs [10]. To increase the volume fraction of CNTs without agglomeration tendency super aligned CNTs have been used by researchers using different techniques. Wardle et al. [11] proposed a method to fabricate CNT/epoxy composite with high volume fraction of CNT up to $22 \%$ using mechanical densification of vertically aligned CNT forests followed by capillarity induced wetting. Wang et al. [10] reported that the waviness, entanglement and poor packing of CNTs also degrade properties of the CNT-based composites. To enhance the mechanical properties, they [10] have also proposed a method of drawing and stretching of the CNTs to reduce the waviness and to increase the volume fraction of CNT up to $46 \%$. Nam et al. [12] fabricated aligned CNT/epoxy composites with a high volume fraction of CNT up to $63.4 \%$ by using a novel combination of stretch-drawing and press winding techniques.

Most of the literature reported on the evaluation of elastic properties and fracture toughness of CNT/epoxy composites at a low volume fraction of the CNT. But a very few analysis on CNT-reinforced laminated composites have been reported. Therefore, in the present study, the elastic properties (i.e. Young's modulus, shear modulus and Poisson's ratio), and mode I fracture energy of $\mathrm{CNT} /$ epoxy laminated composites have been determined with a high volume fraction of CNT up to $60 \%$. Comparative studies between $\mathrm{CNT}$ /epoxy and CF/epoxy laminated composites have also been presented.

\section{Materials and method}

In the present study, single-walled CNT (SWCNT) and carbon fibre (CF) have been considered as the reinforcing materials and epoxy has been considered as the matrix material. The properties of the fibre and the matrix materials $[5,13]$ used in the present analysis are listed in Table 1.

\section{Evaluation of elastic properties of laminated composites} The elastic properties of CNT/epoxy and CF/epoxy composite laminates have been calculated analytically. Various analytical techniques of homogenization such as Reuss model, Voigt model and Periodic microstructure model are available for the evaluation of the elastic properties of the laminated composite. In the present study, the periodic microstructure model [4] has been used for calculation of elastic properties of the laminated composites. Each laminate is composed of four laminas of thickness $0.5 \mathrm{~mm}$ as shown in Fig. 1. The length and breadth of each lamina have been considered as $100 \mathrm{~mm}$ and $20 \mathrm{~mm}$, respectively. The long cylindrical fibres are arranged periodically in a square array $\left(a_{2}=a_{3}\right)$ in the matrix material is shown in Fig. 2.

The random arrangement of fibres in the composite, results in a transversely isotropic material having five independent elastic constants. For transversely isotropic materials, there should be a plane in which the elastic properties are equal in all directions and this plane is called as "plane of isotropy". In the present analysis, the plane $2-3$ is considered as the plane of isotropy. Therefore, the subscripts 2 and 3, use in the symbol of elastic properties are interchangeable. These are reflected in the following Eqs. (2-4). These five independent elastic constants can be determined using the following relations [13].

$$
\begin{aligned}
& E_{1}=C_{11}^{*}-\frac{2 C_{12}^{*^{2}}}{C_{22}^{*}+C_{23}^{*}} \\
& E_{2}=E_{3}=\frac{\left(2 C_{11}^{*} C_{22}^{*}+2 C_{11}^{*} C_{23}^{*}-4 C_{12}^{*^{2}}\right)\left(C_{22}^{*}-C_{23}^{*}+2 C_{44}^{*}\right)}{3 C_{11}^{*} C_{22}^{*}+C_{11}^{*} C_{23}^{*}+2 C_{11}^{*} C_{44}^{*}-4 C_{12}^{*^{2}}} \\
& G_{12}=G_{13}=C_{66}^{*} \\
& v_{12}=v_{13}=\frac{C_{12}^{*}}{C_{22}^{*}+C_{23}^{*}}
\end{aligned}
$$

Table 1 Properties of fibres and matrix materials [5, 13]

\begin{tabular}{lll}
\hline Materials & Young's modulus (GPa) & Poison's ratio \\
\hline $\begin{array}{l}\text { Singe walled carbon nano- } \\
\text { tube }\end{array}$ & 1000 & 0.28 \\
Carbon fibre & 230 & 0.20 \\
Epoxy & 3.89 & 0.37 \\
\hline
\end{tabular}




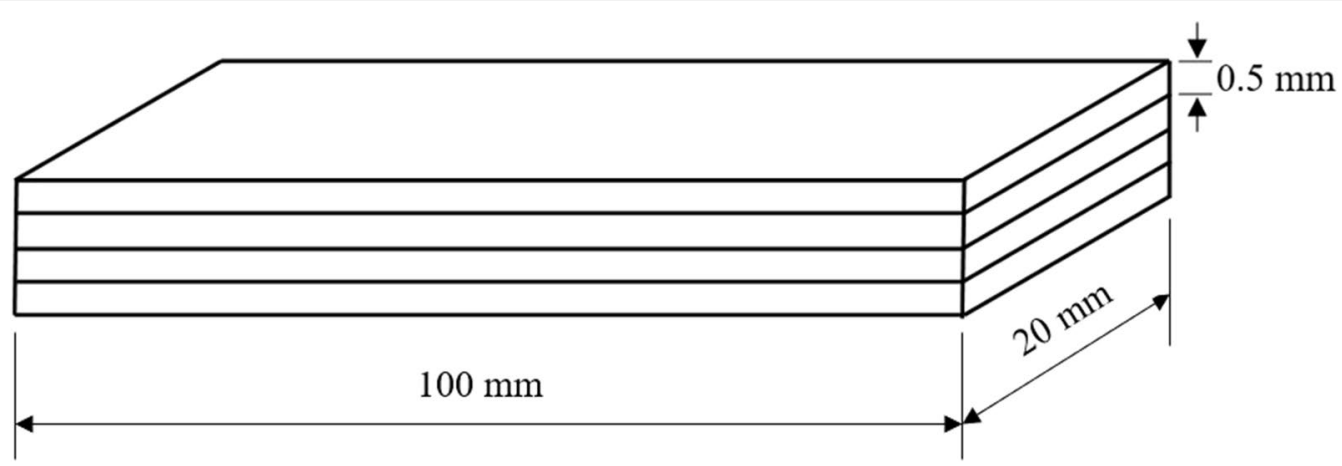

Fig. 1 A laminate is composed of four laminas

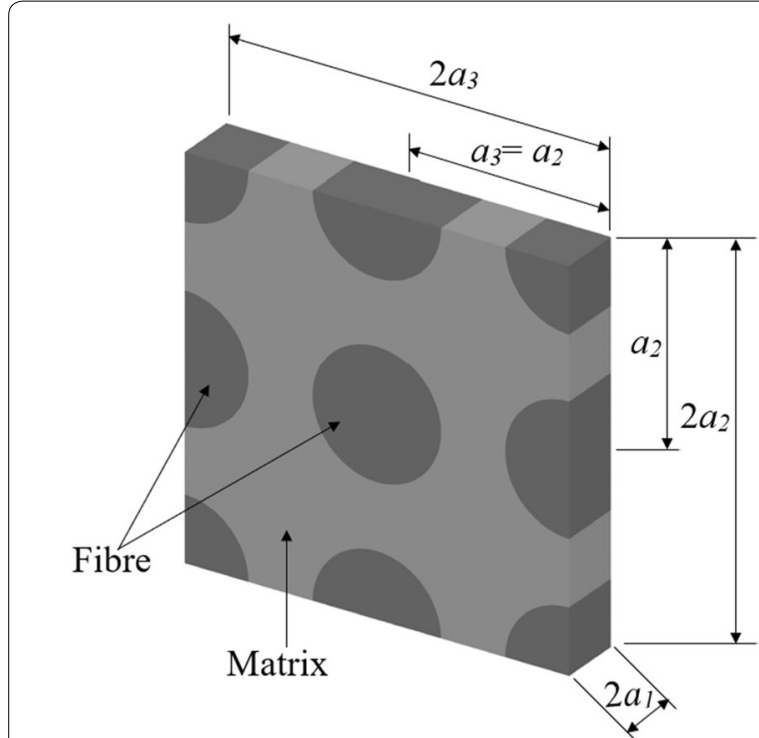

Fig. 2 The periodic microstructure model of a fibre reinforced composite

$$
\begin{aligned}
& v_{23}=\frac{C_{11}^{*} C_{22}^{*}+3 C_{11}^{*} C_{23}^{*}-2 C_{11}^{*} C_{44}^{*}-4 C_{12}^{*^{2}}}{3 C_{11}^{*} C_{22}^{*}+C_{11}^{*} C_{23}^{*}+2 C_{11}^{*} C_{44}^{*}-4 C_{12}^{*^{2}}} \\
& G_{23}=\frac{C_{22}^{*}}{4}-\frac{C_{23}^{*}}{4}+\frac{C_{66}^{*}}{2}=\frac{E_{2}}{2\left(1+v_{23}\right)}
\end{aligned}
$$

where, $C_{11}^{*}, C_{12}^{*}, C_{22}^{*}, C_{23}^{*}, C_{44}^{*}$ and $C_{66}^{*}$ are the components of $C^{*}$ matrix, which is a $6 \times 6$ square symmetric matrix. The components of this $C^{*}$ stiffness matrix are calculated using the following relations [13].

$$
\begin{gathered}
C_{11}^{*}=\lambda_{m}+2 \mu_{m}- \\
\frac{V_{f}}{D}\left[\frac{S_{3}^{2}}{\mu_{m}^{2}}-\frac{2 S_{6} S_{3}}{\mu_{m}^{2} g}-\frac{a S_{3}}{\mu_{m} c}+\frac{S_{6}-S_{7}}{\mu_{m}^{2} g^{2}}+\frac{a S_{6}+b S_{7}}{\mu_{m} g c}+\frac{a^{2}-b^{2}}{4 c^{2}}\right] \\
C_{12}^{*}=\lambda_{m}+\frac{V_{f}}{D} b\left[\frac{S_{3}}{2 c \mu_{m}}-\frac{S_{6}-S_{7}}{2 c \mu_{m} g}-\frac{a+b}{4 c^{2}}\right] \\
C_{23}^{*}=\lambda_{m}+\frac{V_{f}}{D}\left[\frac{a S_{7}}{2 \mu_{m} g c}-\frac{b a+b^{2}}{4 c^{2}}\right] \\
C_{22}^{*}=\lambda_{m}+2 \mu_{m}-\frac{V_{f}}{D}\left[-\frac{a S_{3}}{2 \mu_{m} c}+\frac{a S_{6}}{2 \mu_{m} g c}+\frac{a^{2}-b^{2}}{4 c^{2}}\right] \\
C_{44}^{*}=\lambda_{m}-V_{f}\left[-\frac{2 S_{3}}{\mu_{m}}+\left(\mu_{m}-\mu_{f}\right)^{-1}+\frac{4 S_{7}}{\mu_{m}\left(2-2 v_{m}\right)}\right]^{-1} \\
C_{66}^{*}=\mu_{m}-V_{f}\left[-\frac{S_{3}}{\mu_{m}}+\left(\mu_{m}-\mu_{f}\right)^{-1}\right]^{-1}
\end{gathered}
$$

The value $D, a, b, c, g, \lambda$ and $\mu$ can be calculated using the following relations [13].

$$
\begin{aligned}
D= & \frac{a S_{3}^{2}}{2 \mu_{m}^{2} c}-\frac{a S_{6} S_{3}}{\mu_{m}^{2} g c}+\frac{a\left(S_{6}^{2}-S_{7}^{2}\right)}{2 \mu_{m}^{2} g^{2} c} \\
& +\frac{S_{3}\left(b^{2}-a^{2}\right)}{2 \mu_{m} c^{2}}+\frac{S_{6}\left(a^{2}-b^{2}\right)+S_{7}\left(a b+b^{2}\right)}{2 \mu_{m} g c^{2}} \\
& +\frac{\left(a^{3}-2 b^{3}-3 a b^{2}\right)}{8 c^{3}}
\end{aligned}
$$




$$
\begin{aligned}
a= & \mu_{f}-\mu_{m}-2 \mu_{f} v_{m}+2 \mu_{m} v_{f} \\
b= & -\mu_{m} v_{m}+\mu_{f} v_{f}+2 \mu_{m} v_{m} v_{f}-2 \mu_{f} v_{m} v_{f} \\
c= & \left(\mu_{m}-\mu_{f}\right)\left(\mu_{f}-\mu_{m}+\mu_{f} v_{f}-\mu_{m} v_{m}+2 \mu_{m} v_{f}\right. \\
& \left.-2 \mu_{f} v_{m}+2 \mu_{m} v_{m} v_{f}-2 \mu_{f} v_{m} v_{f}\right) \\
g= & \left(2-2 v_{m}\right) \\
\lambda= & \frac{E}{(1+v)(1-2 v)} \text { and } \mu=G=\frac{E}{2(1+v)}
\end{aligned}
$$

The values $S_{3}, S_{6}$ and $S_{7}$ can be calculated using the following relations [13].

$$
\begin{aligned}
& S_{3}=0.49247-0.47603 V_{f}-0.02748 V_{f}^{2} \\
& S_{6}=0.36844-0.14944 V_{f}-0.27152 V_{f}^{2} \\
& S_{7}=0.12346-0.32035 V_{f}+0.23517 V_{f}^{2}
\end{aligned}
$$

where, the fibres and the matrix are represented by the subscripts $f$ and $m$, respectively. Using the above relations the engineering constant $\left(E_{1}, E_{2}, G_{12}, v_{12}\right.$ and $v_{23}$ ) of a $0^{\circ}$ lamina can be calculated. The compliance matrix $\left[S^{\prime}\right]$ of a $0^{\circ}$ lamina is a $6 \times 6$ matrix [13], which can be calculated using the above elastic constants. The compliance matrix $[S]$ is used for a lamina with any orientation of fibres, which can be calculated using the following relation [13].

$$
[S]=[T]^{T}\left[S^{\prime}\right][T]
$$

where, $[T]$ is the transformation matrix. The stiffness matrix $[C]$ for each lamina in a laminate can be calculated using following equation [13].

$$
[C]=[S]^{-1}
$$

The stiffness matrix of the laminate $[\bar{C}]$ with thickness $t$ and having $N$ number of laminas is calculated using following relation [13].

$$
[\bar{C}]=\sum_{K=1}^{N} \frac{t_{K}}{t}\left[C_{K}\right]
$$

where, " $K$ " indicates $K^{\text {th }}$ lamina of the laminate. Finally, the compliance matrix $[\bar{S}]$ of the laminate is calculated using following relation [13].

$$
[\bar{S}]=[\bar{C}]^{-1}
$$

The Young's modulus, shear modulus and Poison's ratio of a laminate are calculated using following relations [13].

$$
\begin{array}{lll}
E_{x}=1 / S_{11}, & G_{y z}=1 / S_{44}, & v_{y z}=-S_{32} / S_{22} \\
E_{y}=1 / S_{22}, & G_{x y}=1 / S_{66}, & v_{x y}=-S_{21} / S_{11} \\
E_{z}=1 / S_{33}, & G_{x z}=1 / S_{55}, & v_{x z}=-S_{31} / S_{11}
\end{array}
$$

where, $S_{11}, S_{12}$ etc. are the components of the compliance matrix $[\bar{S}]$. MATLAB codes have been developed for calculation of elastic properties of the all laminated composites.

\section{Evaluation of mode I fracture energy of laminated composites}

Double cantilever beam (DCB) made from laminated composites has been used in the present analysis. Figure 3 shows the DCB specimen with an initial crack length of $30 \mathrm{~mm}$. One end of the beam has been fixed and a load has been applied on the other end.

Convergence study has also been performed to decide the FE mesh in the FE model of DCB. For the present $\mathrm{FE}$ analysis, the number of elements has been chosen as $200,400,800$ and 1600 . It has been observed that the load fluctuation with displacement was too high for lower number of elements. After the 400 number of elements, there is a negligible variation of load fluctuations with displacement, but after the 1600 number of elements there is no variation of load fluctuation with displacement. Therefore, it could be concluded that the FE model is converged and for all the FE analysis this FE mesh size has been used.

The DCB has been modelled using FE method in ANSYS. PLANE182 element has been used for FE modelling of the laminas and INTER202 element has been used for FE modelling of the interface between two laminas in laminate. The number of PLANE182 elements and INTER202 elements are 1600 and 280, respectively. Therefore, the total number of elements in the FE model is equal to 1880 . The total number of nodes in the FE model is equal to 2687 . The plane strain condition has

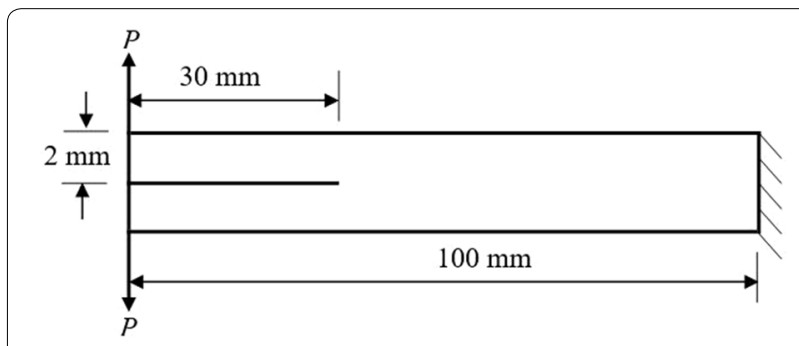

Fig. 3 Double cantilever beam along with initial crack and boundary condition 
been considered for both the elements. In the present study, the linear fracture criterion has been considered. Therefore, the linear material properties of INTER202 element have been used. Figure 4 shows the finite element mesh of DCB specimen along with boundary conditions.

Virtual crack closure technique has been used to find out the reaction force, displacement and the crack extension length. The variation of these reaction forces with corresponding displacements are then plotted to find out the area under the curve. Mode I fracture energy $\left(G_{I}\right)$ of the DCB has been calculated using the following relation [14].

$$
G_{I}=\Delta A / B \Delta a
$$

where, $\Delta A$ is the area under the reaction force versus displacement curve, $\Delta a$ is the crack extension length and $B$ is the breadth of the specimen.

\section{Results and discussion}

The elastic properties i.e. Young's modulus, in-plane shear modulus and Poisson's ratio; and the mode I fracture energy $\left(G_{I}\right)$ of the CNT/epoxy laminated composites have been calculated for different volume fractions of CNT but for CF/epoxy both the properties have been calculated for a constant CF volume fraction of $60 \%$. Three different laminate stacking sequences have also been considered for the calculation of elastic properties and $G_{I}$ of the CNT/epoxy and CF/epoxy laminated composites.

\section{Elastic properties of the CNT/epoxy and CF/epoxy laminated composites}

The elastic properties of the laminated composites have been calculated using Eq. (26). The elastic properties of CNT/epoxy laminated composite at different fibre volume fraction and three stacking sequence of laminates are listed in Table 2.

It could be observed from Table 2 that the transverse Young's moduli $\left(E_{y}\right.$ and $\left.E_{z}\right)$ are not significant compared

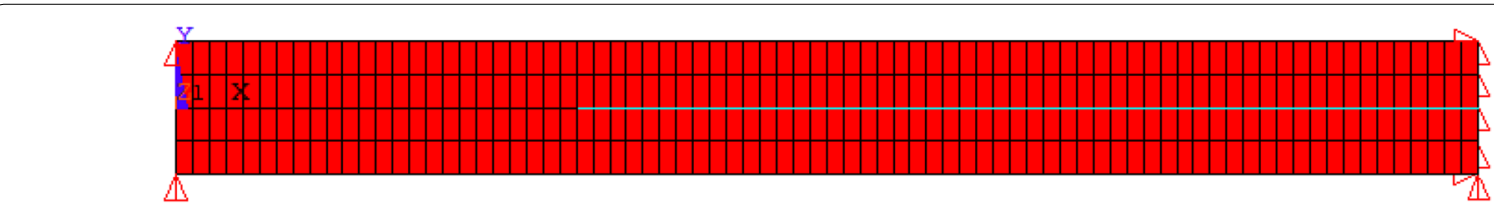

Fig. 4 Finite element mesh of double cantilever beam specimen along with boundary conditions

Table 2 Elastic properties of CNT/epoxy laminated composites at different CNT volume fractions

\begin{tabular}{|c|c|c|c|c|c|c|c|c|c|c|}
\hline \multirow[t]{2}{*}{ Stacking sequence } & \multirow{2}{*}{$\begin{array}{l}\text { Volume fraction } \\
\text { of CNT (\%) }\end{array}$} & \multicolumn{3}{|c|}{ Young's modulus (GPa) } & \multicolumn{3}{|c|}{ Shear modulus (GPa) } & \multicolumn{3}{|c|}{ Poison's ratio } \\
\hline & & $E_{x}$ & $E_{y}$ & $E_{z}$ & $G_{x y}$ & $G_{y z}$ & $G_{x z}$ & $v_{x y}$ & $v_{y z}$ & $v_{x z}$ \\
\hline \multirow[t]{3}{*}[0/0/0/0]{} & 15 & 153.31 & 5.75 & 5.75 & 1.92 & 1.85 & 1.92 & 0.35 & 0.55 & 0.35 \\
\hline & 30 & 302.73 & 7.73 & 7.73 & 2.63 & 2.52 & 2.63 & 0.33 & 0.53 & 0.33 \\
\hline & 60 & 601.57 & 16.88 & 16.88 & 5.67 & 5.79 & 5.67 & 0.31 & 0.45 & 0.31 \\
\hline \multirow[t]{3}{*}{ [0/90/0/90] } & 15 & 79.85 & 79.85 & 7.99 & 1.92 & 1.88 & 1.88 & 0.025 & 0.54 & 0.54 \\
\hline & 30 & 155.65 & 155.65 & 10.53 & 2.63 & 2.57 & 2.57 & 0.016 & 0.52 & 0.52 \\
\hline & 60 & 309.98 & 309.98 & 20.92 & 5.67 & 5.73 & 5.73 & 0.017 & 0.45 & 0.45 \\
\hline \multirow[t]{3}{*}{ [0/30/-30/90] } & 15 & 78.06 & 43.70 & 7.95 & 34.65 & 1.87 & 1.89 & 0.36 & 0.44 & 0.35 \\
\hline & 30 & 153.28 & 84.34 & 10.49 & 64.29 & 2.56 & 2.58 & 0.35 & 0.43 & 0.34 \\
\hline & 60 & 304.97 & 168.38 & 20.86 & 127.31 & 5.74 & 5.71 & 0.35 & 0.37 & 0.29 \\
\hline
\end{tabular}

Table 3 Elastic properties of CF/epoxy laminated composite at $60 \%$ CF volume fraction

\begin{tabular}{|c|c|c|c|c|c|c|c|c|c|c|}
\hline \multirow[t]{2}{*}{ Stacking sequence } & \multirow{2}{*}{$\begin{array}{l}\text { Volume fraction } \\
\text { of CF (\%) }\end{array}$} & \multicolumn{3}{|c|}{ Young's modulus (GPa) } & \multicolumn{3}{|c|}{ Shear modulus (GPa) } & \multicolumn{3}{|c|}{ Poison's ratio } \\
\hline & & $E_{x}$ & $E_{y}$ & $E_{z}$ & $G_{x y}$ & $G_{y z}$ & $G_{x z}$ & $v_{x y}$ & $v_{y z}$ & $v_{x z}$ \\
\hline$[0 / 0 / 0 / 0]$ & 60 & 139.59 & 15.95 & 15.95 & 5.44 & 5.51 & 5.44 & 0.25 & 0.44 & 0.25 \\
\hline$[0 / 90 / 0 / 90]$ & 60 & 78.19 & 78.19 & 18.75 & 5.44 & 5.47 & 5.47 & 0.05 & 0.39 & 0.39 \\
\hline$[0 / 30 /-30 / 90]$ & 60 & 73.78 & 45.43 & 18.67 & 39.06 & 5.48 & 5.46 & 0.38 & 0.33 & 0.24 \\
\hline
\end{tabular}


to the longitudinal Young's modulus $\left(E_{x}\right)$ for [0/0/0/0] laminated composites. As expected for [0/90/0/90] laminated composite that precisely the same value of the $E_{x}$ and transverse Young's modulus in the $y$-direction $\left(E_{y}\right)$ has been observed from Table 2. The elastic properties of CF/epoxy composites have been calculated at a constant CF volume fraction of $60 \%$ for different stacking sequences of laminates are listed in Table 3.

\section{Variation of longitudinal Young's modulus}

The variation of longitudinal Young's modulus $\left(E_{x}\right)$ of $\mathrm{CNT} /$ epoxy composite has been calculated with volume fraction for different stacking sequence of laminates. Figure 5 shows that the variation of $E_{x}$ of CNT/epoxy composite with CNT volume fraction as compared to the $E_{x}$ of CF/epoxy composite at a constant CF volume fraction of $60 \%$ for $[0 / 0 / 0 / 0]$ stacking sequence of laminate. It has been observed from Fig. 5 that with the addition of only $15 \%$ CNT in epoxy will give a higher value of $E_{x}$ as compared to addition of $60 \% \mathrm{CF}$ in epoxy. After $15 \%$ fibre volume fraction of CNT the value of $E_{x}$ for CNT/ epoxy composite becomes significantly higher than that of CF/epoxy with $60 \% \mathrm{CF}$ volume fraction. It has also been observed from Fig. 5 that the value of $E_{x}$ of CNT/ epoxy becomes $330.95 \%$ higher than that of $\mathrm{CF} /$ epoxy at a constant fibre volume fraction $60 \%$.

A similar type of analysis has also been performed for [0/90/0/90] and [0/30/-30/90] laminate configurations. Figures 6 and 7 show that the variation of $E_{x}$ of $C N T /$ epoxy composite with CNT volume fraction as compared to the $E_{x}$ of CF/epoxy composite at a constant CF volume fraction of $60 \%$ for $[0 / 90 / 0 / 90]$ and $[0 / 30 /-30 / 90]$ laminate configurations, respectively.

It can be seen from Fig. 6 and that with the addition of only $15 \%$ CNT in epoxy will give almost the same value

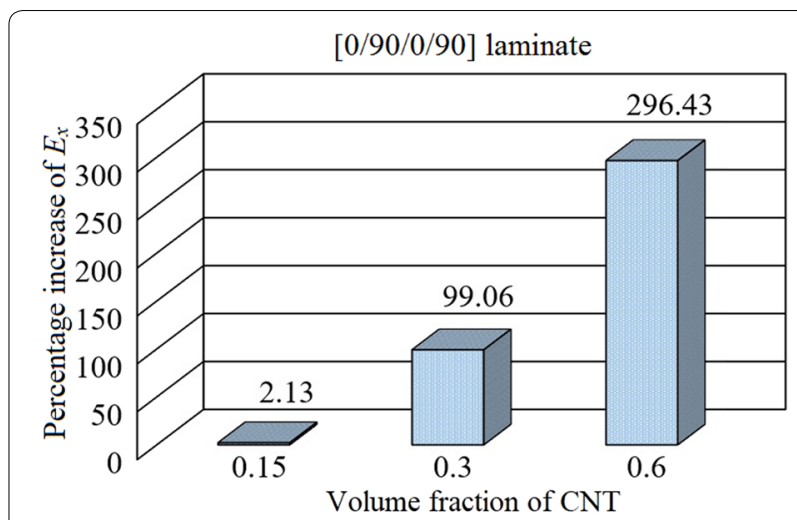

Fig. 6 Percentage increase in $E_{x}$ of CNT/epoxy with volume fraction as compared to CF/epoxy at a constant $60 \%$ CF volume fraction for [0/90/0/90] stacking sequence of laminate

of $E_{x}$ as compared to the addition of $60 \%$ CF in epoxy. A maximum increase of $296.43 \%$ has been observed for $\mathrm{CNT} / \mathrm{epoxy}$ as compared to CF/epoxy for the same fibre volume fraction of $60 \%$ for [0/90/0/90] laminate configuration. But for $[0 / 30 /-30 / 90]$ laminate configuration the maximum increase of $313.33 \%$ has been observed for CNT/epoxy composite as compared to CF/epoxy composite with the same fiber volume fraction of $60 \%$. Therefore, it could be concluded that a similar trend of percentage increase in $E_{x}$ with CNT volume fraction has been observed from Figs. 5, 6, 7 for all the stacking sequences of composite laminates. The strength of the laminated composites depends on the stacking sequence of different laminae in the laminate, therefore, for a particular volume fraction, the values of the percentage increase in $E_{x}$ are different.
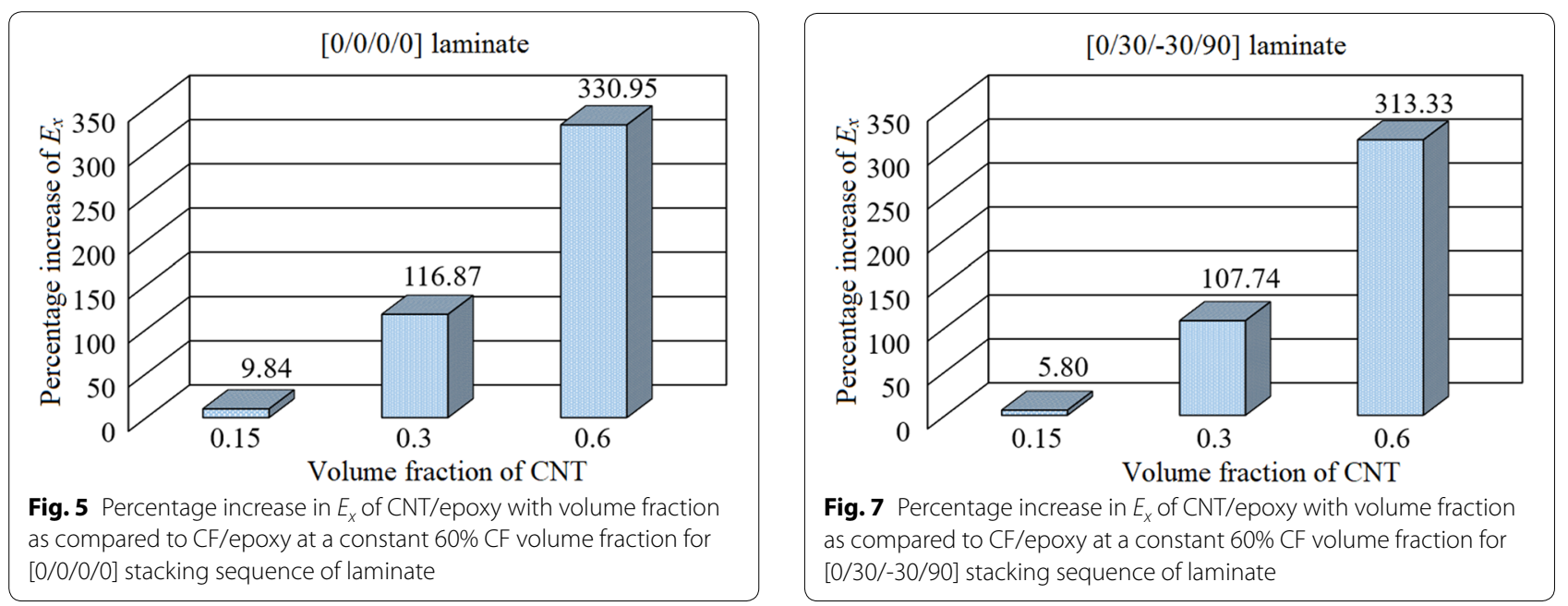


\section{Variation of transverse Young's modulus and in-plane shear modulus}

It can be observed from Table 2 that the transverse Young's modulus and in plane shear modulus have also been increased with increase in fibre volume fractions for all the three stacking sequences of composite laminates. It can also be observed from Tables 2 and 3 that for $[0 / 0 / 0 / 0]$ laminate configuration the values of transverse Young's modulus and in plane shear modulus of CNT/ epoxy composite are almost same compared to CF/epoxy composite at a constant fibre volume fraction of $60 \%$. In case of [0/90/0/90] laminated configuration the values of Young's modulus along $x$ and $y$ directions $\left(E_{x}\right.$ and $\left.E_{y}\right)$ of CNT/epoxy composite are significant compared to CF/ epoxy composite for a constant fiber volume fraction of $60 \%$. But for the same laminated configuration the other elastic properties of $\mathrm{CNT} /$ epoxy composite are not significant compared to CF/epoxy composite. For [0/30/30/90] laminate configuration, the values of $E_{x}, E_{y}$ and in-plane shear modulus in the $x-y$ plane $\left(G_{x y}\right)$ of $\mathrm{CNT} /$ epoxy composite are significant compared to CF/epoxy at a constant volume fraction of $60 \%$.

The strength of a lamina depends on the orientation of fibers in the lamina. The strength of the laminated composites depends on the stacking sequences of different laminae in the laminate, since a laminate is fabricated by stacking different laminae. Therefore, the values of the elastic properties are also depends on the laminate configuration. In the present study, three stacking sequences of the laminates viz.[0/0/0/0], [0/90/0/90] and $[0 / 30 /-30 / 90]$ have been considered in which the fibers are mainly oriented in $x$ and $y$ directions. Therefore, for the above three stacking sequences of laminate configurations, the elastic properties of $E_{x}, E_{y}$ and $G_{x y}$ are more significant compared to the other elastic properties.

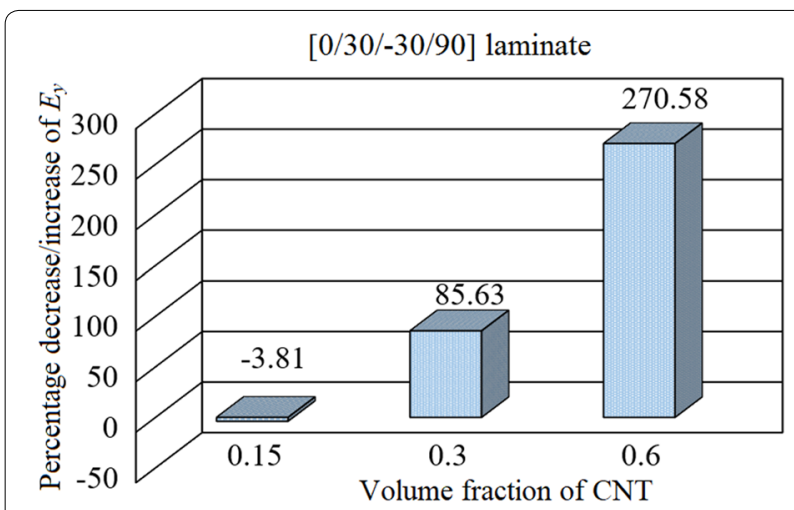

Fig. 8 Percentage increase/decrease in $E_{y}$ of CNT/epoxy with volume fraction as compared to CF/epoxy at a constant 60\% CF volume fraction for [0/30/-30/90] stacking sequence of laminate

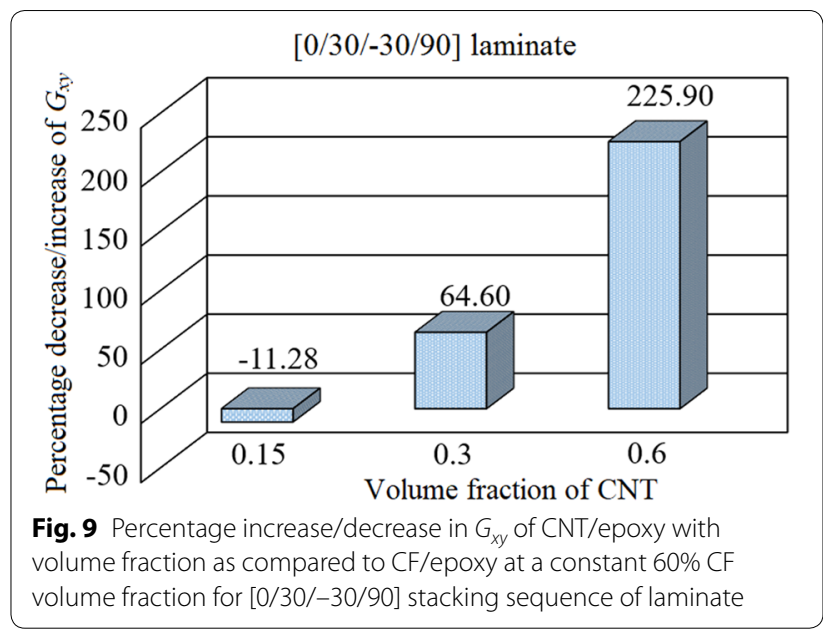

Since the variation of $E_{z}, G_{y z}$ and $G_{x z}$ of CNT/epoxy composite are not significant compared to $\mathrm{CF} /$ epoxy composite for a constant CF volume fraction of $60 \%$, therefore, the variation of $E_{y}$ and $G_{x y}$ have been presented for the present study. Figures 8 and 9 show the percentage increase/decrease of $E_{y}$ and $G_{x y}$ of CNT/epoxy composite with volume fraction compare to the $\mathrm{CF} /$ epoxy composite for a constant fiber volume fraction of $60 \%$ for $[0 / 30 /-30 / 90]$ laminated composite.

It can be seen from Figs. 8 and 9 that at $15 \%$ fibre volume fraction, the values of $E_{y}$ and $G_{x y}$ for CNT/epoxy is slightly lower than that of CF/epoxy with $60 \%$ fibre volume fraction. After 15\% CNT volume fraction, the values of $E_{y}$ and $G_{x y}$ for CNT/epoxy significantly increase compared to $\mathrm{CF} /$ epoxy with $60 \% \mathrm{CF}$ volume fraction. At $60 \% \mathrm{CNT}$ volume fraction, $E_{y}$ for CNT/epoxy becomes $270.58 \%$ higher as compared to CF/epoxy with $60 \% \mathrm{CF}$ volume fraction. Similarly, for $G_{x y}$ an increase of $225.90 \%$ has been observed for CNT/epoxy as compared to CF/ epoxy at a constant fiber volume fraction of $60 \%$. A similar trend of percentage increase/decrease of $E_{y}$ and $G_{x y}$ of $\mathrm{CNT} /$ epoxy composite with volume fraction compare to the CF/epoxy composite for a constant $60 \%$ CF volume fraction have also been observed for others two types of laminated composites.

Kormanikova and Kotrasova [4] calculated the elastic properties of the unidirectional lamina as well as effective elastic properties for a $[0 / 45 /-45 / 90]_{\mathrm{S}}$ laminate with a thickness of lamina equal to $0.125 \mathrm{~mm}$. The elastic properties of $[0 / 45 /-45 / 90]_{\mathrm{s}}$ laminate with $0.125 \mathrm{~mm}$ thickness of lamina have also been calculated to validate the present study and similar values of elastic properties have been found as reported by Kormanikova and Kotrasova [4]. 


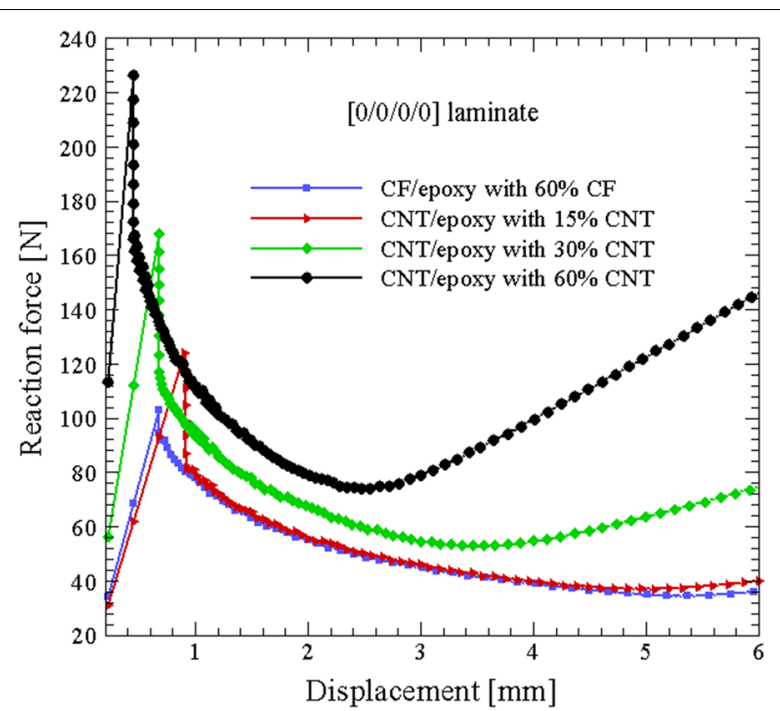

Fig. 10 Variation of reaction force with displacement at different fibre volume fractions for [0/0/0/0] stacking sequence of laminate

\section{Mode-I fracture energy of the CNT/epoxy and CF/epoxy laminated composites}

Finite element analysis has been performed of DCB made from CNT/epoxy and CF/epoxy laminated composite. The elastic properties calculated using periodic microstructure model has been used in FE analysis of the DCB in ANSYS. The variation of reaction force with displacement is shown in the following figures. Figure 10 shows the variation of reaction force with displacement at different fibre volume fractions for $[0 / 0 / 0 / 0]$ laminate.

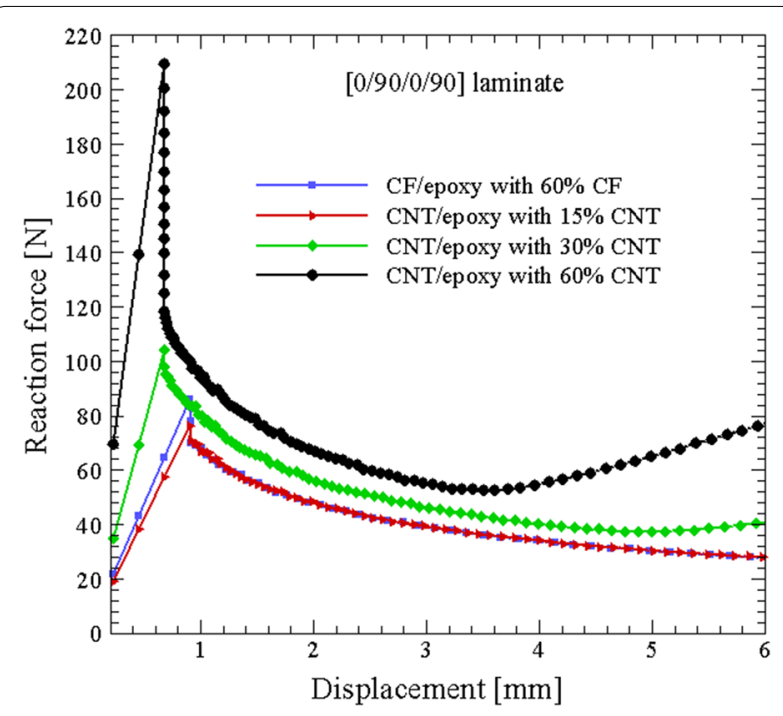

Fig. 11 Variation of reaction force with displacement at different fibre volume fractions for [0/90/0/90] stacking sequence of laminate

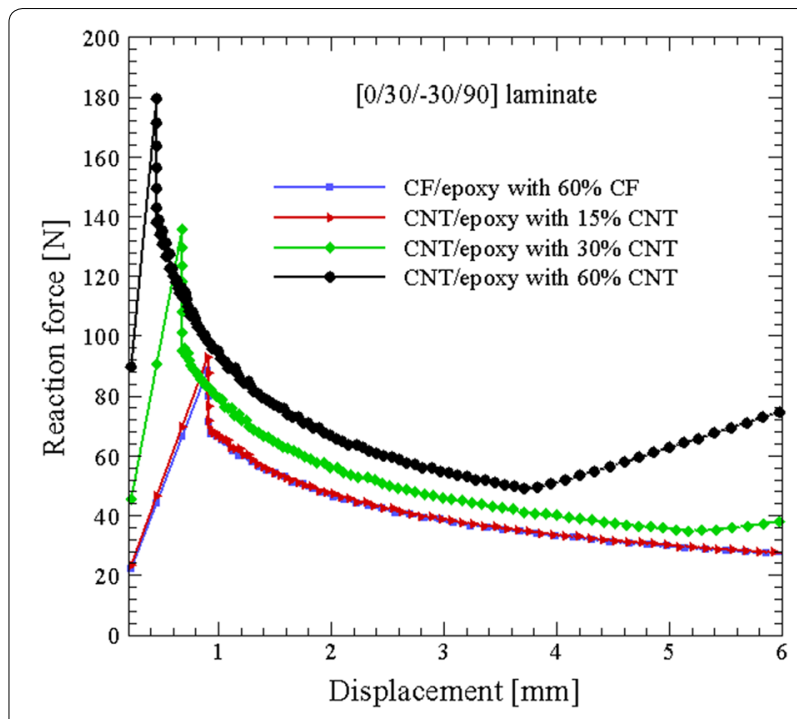

Fig. 12 Variation of reaction force with displacement at different fibre volume fractions for [0/30/-30/90] stacking sequence of laminate

It can be seen from Fig. 10 that the critical load is highest for [0/0/0/0] laminated CNT/epoxy composite at $60 \% \mathrm{CNT}$ volume fraction. It can also be seen from Fig. 10 that the critical load is lowest for CF/epoxy laminated composite though the volume fraction of $\mathrm{CF}$ is $60 \%$. Figures 11 and 12 show the variation of reaction force with displacement at different fibre volume fractions of DCB made from [0/90/0/90] and [0/30/-30/90] laminates, respectively.

A similar trend has been observed for both of these laminate configurations as observed for [0/0/0/0] laminate configuration. The highest critical load has been observed at $60 \% \mathrm{CNT}$ volume fraction for all the three laminate configurations.

The area under the reaction forces and corresponding displacements curve and crack extension length have been found from the FE analysis of the DCB specimens using virtual crack closure technique. Then mode-I fracture energy $\left(G_{I}\right)$ has been calculated for the DCB made from all the laminated composites using Eq. (27). The crack extension length $(\Delta a)$, the area under the reaction force vs. displacement curve $(\Delta A), G_{I}$ and percentage increase/decrease in $G_{I}$ have been listed in Table 4.

It could be observed from Table 4 that with the addition of $15 \%$ CNT in epoxy will give almost the same value of $G_{I}$ when $60 \%$ CF is added to epoxy for all the three types of stacking sequences of laminated composites. The maximum value of $G_{I}$ has been found to be $0.667 \mathrm{~J} / \mathrm{mm}^{2}$ for [0/0/0/0] laminated CNT/epoxy composite. An increase of $G_{I}$ has been found by $173.87 \%$ for CNT/epoxy composite compared to CF/epoxy composite at a constant 
Table 4 Percentage increase/decrease in mode I fracture energy of the CNT/epoxy with volume fraction compared to CF/ epoxy composite at a constant CF volume fraction of $60 \%$

\begin{tabular}{|c|c|c|c|c|c|c|}
\hline Material & Laminate configuration & $\begin{array}{l}\text { Volume fraction } \\
\text { (\%) }\end{array}$ & $\Delta a(\mathrm{~mm})$ & $\Delta A(\mathrm{~N} \mathrm{~mm})$ & $G_{l}\left(\mathrm{~J} / \mathrm{mm}^{2}\right)$ & $\begin{array}{l}\% \text { increase/ } \\
\text { decrease in } G_{I} \\
(\%)\end{array}$ \\
\hline CF/epoxy & {$[0 / 0 / 0 / 0]$} & 60 & 58.50 & 285.246 & 0.24380 & - \\
\hline \multirow[t]{3}{*}{ CNT/epoxy } & {$[0 / 0 / 0 / 0]$} & 15 & 62.50 & 295.914 & 0.23673 & -2.89 \\
\hline & & 30 & 53.50 & 402.931 & 0.37657 & 54.46 \\
\hline & & 60 & 46.00 & 614.285 & 0.66770 & 173.87 \\
\hline CF/epoxy & [0/90/0/90] & 60 & 56.50 & 239.351 & 0.21181 & - \\
\hline \multirow[t]{3}{*}{ CNT/epoxy } & [0/90/0/90] & 15 & 55.25 & 235.798 & 0.21339 & 0.75 \\
\hline & & 30 & 57.75 & 296.463 & 0.25667 & 21.18 \\
\hline & & 60 & 52.50 & 419.856 & 0.39986 & 88.78 \\
\hline CF/epoxy & [0/30/-30/90] & 60 & 55.75 & 236.373 & 0.21199 & - \\
\hline \multirow[t]{3}{*}{ CNT/epoxy } & [0/30/-30/90] & 15 & 57.00 & 240.932 & 0.21134 & -0.30 \\
\hline & & 30 & 58.50 & 301.509 & 0.25770 & 21.56 \\
\hline & & 60 & 51.75 & 407.321 & 0.39354 & 85.64 \\
\hline
\end{tabular}

volume fraction of $60 \%$ for $[0 / 0 / 0 / 0]$ stacking sequence of laminate. But for [0/90/0/90] and [0/30/-30/90] stacking sequences of $\mathrm{CNT} /$ epoxy composite laminates the increase in $G_{I}$ have been found $88.78 \%$ and $85.65 \%$, respectively compared to $\mathrm{CF} /$ epoxy composite at $60 \%$ fibre volume fraction. It could be concluded that the percentage increase of $G_{I}$ for [0/90/0/90] and [0/30/-30/90] laminated composites are almost the same. Therefore, it could be concluded that the maximum increase in $G_{I}$ has been observed for $[0 / 0 / 0 / 0]$ laminate configuration. The value of $G_{I}$ for [0/0/0/0] laminate configuration is two times higher than the other two laminate configurations.

The authors have not found any kind of literature on the determination of mode I fracture energy of CNT/ epoxy laminated composite. Due to this, the authors have not compared the present FE result of mode I fracture energy with any existing literature. But the trend of the variation of reaction vs. displacement curve of the present advanced CNT/epoxy composite are similar in nature to the conventional glass/epoxy unidirectional laminated composite as reported by Samborski et al. [15]. Elastic properties and mode I fracture energy of $\mathrm{CNT} /$ epoxy and CF/epoxy laminated composite have been calculated and then compared. In the future, the $\mathrm{CF} /$ epoxy laminated composites may be replaced by CNT/epoxy laminated composites. Therefore, the present study may provide valuable information to the future researcher about the importance of CNT-reinforced laminated composites for potential future applications since a few numbers of literatures have been reported on the fracture analysis of CNT/epoxy laminated composites.

\section{Conclusions}

Elastic properties of CNT/epoxy and CF/epoxy laminated composites with three stacking sequences have been calculated analytically and mode-I fracture energy of double cantilever beams made from those laminated composites have been determined computationally using FE method. To understand the importance of the CNT-reinforced laminated composites over conventional laminated composite, a comparison has also been presented between CNT/epoxy and CF/epoxy laminated composites. Some of the important conclusions drawn from the present study are -

- The addition of only one-fourth amount of CNT in epoxy as compared to CF in epoxy will give almost the same values of longitudinal Young's modulus $\left(E_{x}\right)$ and mode I fracture energy $\left(G_{I}\right)$.

- The $E_{x}$ of CNT/epoxy composite has been found $330.95 \%$ higher compared to the CF/epoxy composite at a constant fiber volume fraction of $60 \%$ for $[0 / 0 / 0 / 0]$ stacking sequence of laminate.

- The variation of $E_{x}, E_{y}$ and $G_{x y}$ are significant compared to other elastic properties.

- The mode I fracture energy of CNT/epoxy composite has been determined $173.87 \%$ higher compared to the CF/epoxy at a constant fibre volume fraction of $60 \%$ for $[0 / 0 / 0 / 0]$ stacking sequence of laminate.

- The percentage increase of $G_{I}$ for [0/90/0/90] and $[0 / 30 /-30 / 90]$ laminated composites are almost the same.

- The value of $G_{I}$ for $[0 / 0 / 0 / 0]$ laminated composite is two times higher than the other two types of laminated composites. 


\section{Acknowledgements}

The authors would like to thanks to the Department of Mechanical Engineering, Tezpur University for providing us computational facility in CAD laboratory.

\section{Authors' contributions}

$J B$ is an M.Tech student therefore he has worked under my guidance. He has developed MATLAB code as well as finite element analysis using ANSYS software. Whenever he has faced technical problems, as a supervisor I have helped him. Both authors read and approved the final manuscript.

\section{Funding}

Not applicable.

\section{Availability of data and materials}

Not applicable.

\section{Competing interests}

The author declare that we have no competing interest.

Received: 27 February 2020 Accepted: 24 September 2020

Published online: 07 October 2020

\section{References}

1. lijima S (1991) Helical microtubules of graphitic carbon. Nature 354:5658. https://doi.org/10.1038/354056a0

2. Kirtania S, Chakraborty D (2014) Fracture behaviour of carbon nanotubebased composites with a broken fiber using multi-scale finite element modeling. J Comput Theor Nanosci 11:676-684. https://doi.org/10.1166/ jctn.2014.3411

3. Kausar A, Rafique I, Muhammad B (2016) Review of applications of polymer/carbon nanotubes and epoxy/CNT composites. Polym Plast Technol Eng 55:1167-1191. https://doi.org/10.1080/03602559.2016.1163588

4. Kormanikova E, Kotrasova K (2011) Elastic mechanical properties of fiber reinforced composite material. Chem Listy 105:5758-s762

5. Kirtania S, Chakraborty D (2018) Determination of thermoelastic properties of carbon nanotube/epoxy composites using finite element method J Mater Eng Performance 27:3783-3788. https://doi.org/10.1007/s1166 5-017-2981-3

6. Kageyama T, Shinozaki K, Zhang L, Lu J, Takaki H, Lee S-S (2018) Fabrication of an Au-Au/carbon nanotube-composite contacts RF-MEMS switch. Micro Nano Syst Lett 6:6. https://doi.org/10.1186/s40486-018-0068-z
7. Zhou H, Du X, Liu HY, Zhou H, Zhang Y, Mai YW (2017) Delamination toughening of carbon fiber/epoxy laminates by hierarchical carbon nanotube-short carbon fibre interleaves. Compos Sci Technol 140:46-53. https://doi.org/10.1016/j.compscitech.2016.12.018

8. Li N, Wang Gd, Melly SK, Peng T, Li YC, Zhao QD, Ji Sd (2019) Interlaminar properties of GFRP laminates toughened by CNTs buckypaper interlayer. Compos Struct 208:13-22. https://doi.org/10.1016/j.compstruct 2018.10 .002

9. Quan D, Urdaniz JL, Ivankovic A (2018) Enhancing mode-I and mode-II fracture toughness of epoxy and carbon fibre reinforced epoxy composites using multi-walled carbon nanotubes. Mater Des 143:81-92. https:// doi.org/10.1016/j.matdes.2018.01.051

10. Wang X, Bradford PD, Liu W, Zhao H, Inoue Y, Maria JP, Li Q, Yuan FG, Zhu Y (2011) Mechanical and electrical property improvement in CNT/ Nylon composites through drawing and stretching. Compos Sci Technol 71:1677-1683. https://doi.org/10.1016/j.compscitech.2011.07.023

11. Wardle BL, Saito DS, Garcia EJ, Hart AJ, de Villoria RGD, Verploegen EA (2008) Fabrication and characterization of ultrahigh-volume-fraction aligned carbon nanotube-polymer composites. Adv Mater 20:27072714. https://doi.org/10.1002/adma.200800295

12. Nam TH, Goto K, Yamaguchi Y, Premalal EVA, Shimamura Y, Inoue Y, Arikawa S, Yoneyama S, Ogihara S (2016) Improving mechanical properties of high-volume fraction aligned multi-walled carbon nanotube/epoxy composites by stretching and pressing. Compos Part B 85:15-23. https:// doi.org/10.1016/j.compositesb.2015.09.012

13. Barbero EJ (2014) Finite element analysis of composite materials using ANSYS. CRC Press, Taylor \& Francis Group, New York

14. Karapappas P, Vavouliotis A, Tsotra P, Kostopoulos V, Paipetis A (2009) Enhanced fracture properties of carbon reinforced composites by the addition of multi-wall carbon nanotubes. J Compos Mater 43:977-985. https://doi.org/10.1177/0021998308097735

15. Samborshi S, Gliszczynski A, Rzeczkowski J, Wiacek N (2019) Mode I interlaminar fracture of glass/epoxy unidirectional laminates. Part I: Experimental study. Materials 12:1607. https://doi.org/10.3390/ma121 01607

\section{Publisher's Note}

Springer Nature remains neutral with regard to jurisdictional claims in published maps and institutional affiliations.

\section{Submit your manuscript to a SpringerOpen ${ }^{\circ}$ journal and benefit from:}

- Convenient online submission

- Rigorous peer review

- Open access: articles freely available online

- High visibility within the field

- Retaining the copyright to your article

Submit your next manuscript at $\boldsymbol{\nabla}$ springeropen.com 